\title{
Herbicidas Inibidores da ALS Aplicados em Pós-Emergência no ArRoz de Terras Altas ${ }^{1}$
}

\author{
ALS-inhibiting Herbicides Applied in Upland-Rice Post-emergence
}

PETTER, F.A. ${ }^{2}$, PACHECO, L.P. ${ }^{2}$, ZUFFO, A.M. ${ }^{3}$, ALCÂNTARA NETO, F. ${ }^{2}$ e RIBEIRO, W.R.M. ${ }^{3}$

\begin{abstract}
RESUMO - Este trabalho teve por objetivo avaliar a seletividade de herbicidas inibidores da ALS recomendados para arroz irrigado, quando aplicados em diferentes estádios de desenvolvimento do arroz de terras altas. O experimento foi conduzido em campo, no município de Nova Xavantina-MT, no período de novembro de 2009 a abril de 2010. O delineamento experimental foi o de blocos ao acaso, em esquema fatorial $5 \times 3$, composto pelos tratamentos herbicidas penoxsulam (36 $\left.\mathrm{g} \mathrm{ha}^{-1}\right)$, bispyribac-Na $\left(50 \mathrm{~g} \mathrm{ha}^{-1}\right)$, pirazosulfuron-ethyl $\left(20 \mathrm{~g} \mathrm{ha}^{-1}\right)$ e 2,4-D (670 $\mathrm{g} \mathrm{ha}^{-1}$ ) e pela testemunha capinada. Os herbicidas foram aplicados em três épocas: 15, 30 e 45 dias após a emergência (DAE), perfazendo 15 tratamentos, com quatro repetições. Aos 7, 14 e 28 dias após a aplicação (DAA) dos herbicidas foram realizadas as seguintes avaliações: fitotoxicidade à cultura, altura de plantas, fitomassa, quantidade de panículas por metro quadrado, grãos por panícula e produtividade. Os maiores indices de fitotoxicidade foram observados nas plantas tratadas com bispyribac-Na, aplicado aos 15 e 30 DAE. As plantas de arroz conseguiram se recuperar quanto à altura de plantas provocada pelos herbicidas a partir de 28 DAA. No que se refere aos herbicidas inibidores da ALS, o penoxsulam, aplicado aos $30 \mathrm{DAE}$, apresentou potencialidade para ser utilizado no arroz de terras altas, por não reduzir a produtividade de grãos.
\end{abstract}

Palavras-chave: penoxsulam, bispyribac-Na, pirazosulfuron-ethyl, fitotoxicidade, produtividade.

\begin{abstract}
This study aimed to evaluate the selectivity of the ALS-inhibitors recommended for flooded rice when applied at different development stages of upland rice. The experiment was conducted in the field, in Nova Xavantina-MT, from November 2009 to April 2010, arranged in a randomized block design in a factorial scheme $5 \times 3$,consisting of the herbicide treatments (penoxsulam

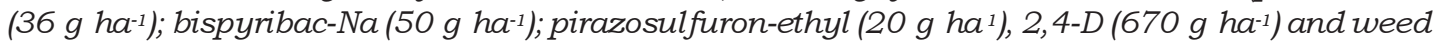
control. The herbicides were applied at 15, 30, and 45 days after emergence (DAE), totaling 15 treatments with four replications. At 7, 14, and 28 days after herbicide application (DAA), the following assessments were carried out: crop phytotoxicity, plant height, biomass, number of panicle $m^{-2}$, grains per panicle-1 and productivity. The highest phytotoxicity rates were observed in plants treated with bispyribac- $\mathrm{Na}$, applied at 15 and $30 \mathrm{DAE}$. The rice plants recovered from plant height reduction caused by the herbicides after $28 \mathrm{DAA}$. As to the ALS-inhibitors, penoxsulam showed potential for use in upland rice, since it does not reduce rice productivity.
\end{abstract}

Keywords: penoxsulam, bispyribac-Na, pirazosulfuron-ethyl, phytotoxicity, productivity.

\section{INTRODUÇÃO}

O Brasil tem papel importante na produção de alimentos, com destaque para o cultivo de cereais. Na safra 2009/10 o País produziu 148 milhões de toneladas de grãos, com soja e milho ocupando mais de 60\% desse total. Nesse cenário, a cultura do arroz

1 Recebido para publicação em 23.4.2011 e aprovado em 19.3.2012.

2 Professor, Programa de Pós-Graduação em Agronomia-Fitotecnia, Universidade Federal do Piauí, Campus Prof ${ }^{\mathrm{a}}$. Cinobelina Elvas - UFPI/CPCE, 64.900-000 Bom Jesus-PI, <petter@ufpi.edu.br>; <leandroppacheco@gmail.com>; fneto@ufpi.edu.br>; ${ }^{3}$ Mestrando em Agronomia-Fitotecnia, UFPI/CPCE, <alan_zuffo@hotmail.com; wendellrezende@yahoo.com.br>. 
representa $8 \%$ da produção de cereais, com 11,3 milhões de toneladas, apresentando, na região Sul, mais de $45 \%$ da área cultivada, o que corresponde a $70 \%$ da produção brasileira de arroz. Nessa região há predominância do arroz irrigado por inundação, com produtividade média de $6.400 \mathrm{~kg} \mathrm{ha}^{-1}$ (CONAB, 2010). Todavia, a expansão desse modelo de produção tem sido limitada pelo elevado custo e demanda de água para realizar a inundação dos tabuleiros.

Na safra 2009/ 10 a demanda de arroz em casca no Brasil foi de 12,2 milhões de toneladas (CONAB, 2010), o que serve de alerta quanto à necessidade de aumento na produção nacional. $\mathrm{O}$ arroz de terras altas, cultivado em condições de sequeiro, tem sido apontado como alternativa para ampliar a produção, em razão dos menores impactos ambientais e menores custos em relação ao sistema inundado (Wander, 2006).

Ao considerar que as culturas com maior difusão no cerrado são o milho e a soja (CONAB, 2010), tem-se um ciclo de monocultura, desfavorecendo os benefícios que a rotação de cultura traz ao sistema agrícola, como maior exploração dos perfis do solo (Costa et al., 2004), interrupção dos ciclos biológicos de pragas e doenças, além da diversificação da meso e microfauna do solo (Gasparim et al., 2005). Viabilizar o cultivo do arroz de sequeiro em sistema convencional ou direto de semeadura pode se constituir em mais uma opção para a diversificação de culturas no cerrado.

A dificuldade no controle de plantas daninhas na cultura do arroz de terras altas tem sido um dos desafios para sua expansão no programa de rotação de culturas no cerrado, uma vez que as áreas cultivadas com soja e milho apresentam elevadas infestações de plantas daninhas (Cobucci \& Portella, 2001; Pacheco et al., 2009). Além do mais, o arroz de terras altas apresenta poucas opções de herbicidas, o que aumenta o risco dessa atividade.

De acordo com Cobucci \& Portela (2001), a carência de produtos e tecnologia para o controle de plantas daninhas em cultivo de arroz de terras altas, somada à baixa capacidade de competição do arroz com essas invasoras, constitui um dos principais obstáculos para a introdução da cultura em sistemas agrícolas de manejo intensivo. Segundo esses autores, devido ao crescimento inicial lento e ao baixo porte das espécies modernas cultivadas, a cobertura do solo só ocorre entre 40 e 50 dias após a semeadura. Segundo Rahmam (1992), a cultura do arroz deve permanecer livre da presença de plantas daninhas entre 15 e 45 dias após a emergência.

Ao se considerar que o controle químico de plantas daninhas tem sido tática indispensável ao cultivo em larga escala (Rajguru et al., 2005), estudos que possam avaliar opções de herbicidas com potencial para serem utilizados em pós-emergência da cultura do arroz podem contribuir para o manejo integrado (Andes et al., 2007). Herbicidas recomendados para o arroz irrigado, com destaque para os inibidores da ALS (acetolactato sintetase), precisam ser testados, a fim de integrar o manejo integrado de plantas daninhas no arroz de terras altas (Carlesso et al., 1998; Andes et al., 2007). Segundo Leite et al. (1998) e Vidal (2002), esses produtos apresentam amplo espectro de ação, baixa toxicidade a homem e animais e alta sistemicidade.

Para o arroz cultivado em sistema irrigado, existem diversos trabalhos que avaliam a eficiência no uso de diferentes herbicidas (Concenço et al., 2006; Machado et al., 2006; Sanchotene et al., 2009). Todavia, o arroz de terras altas, por ser considerado, de forma equivocada, cultura marginal no cerrado, de baixo custo, não tem despertado interesse por parte das empresas privadas em estudos para disponibilizar novas opções de herbicidas para essa modalidade de cultivo.

Espera-se, com este trabalho, apresentar possiveis opções para uso de herbicidas já utilizados em arroz irrigado, com potencialidades de ser recomendado para o arroz de terras altas. Diante disso, este trabalho teve por objetivo avaliar a seletividade de herbicidas inibidores da ALS quanto ao desenvolvimento e à produtividade do arroz de terras altas.

\section{MATERIAL E MÉTODOS}

O experimento foi conduzido em campo, no município de Nova Xavantina-MT, com localização geodésica de $14^{\circ} 41^{\prime} 46^{\prime \prime}$ de latitude $\mathrm{S}$ e $52^{\circ} 20^{\prime} 53^{\prime \prime}$ de longitude W e altitude de 
$310 \mathrm{~m}$, no período de novembro de 2009 a abril de 2010, em solo classificado como Latossolo Vermelho distrófico - LVd (Embrapa, 1999).

A análise textural do solo, na camada de $0-20 \mathrm{~cm}$, apresentou $400 \mathrm{~g} \mathrm{~kg}^{-1} \mathrm{de}$ argila, $100 \mathrm{~g} \mathrm{~kg}^{1}$ de silte e $500 \mathrm{~g} \mathrm{~kg}^{-1}$ de areia. As composições químicas do solo estão apresentadas na Tabela 1. O clima da região é do tipo Aw, segundo a classificação de Köppen, com duas estações bem definidas: uma seca, de maio a setembro, e outra chuvosa, de outubro a abril. As condições climáticas ocorridas durante a realização do experimento estão na Figura 1.

$\mathrm{O}$ arroz foi cultivado em sistema de plantio convencional, sendo realizada uma operação de preparo de solo com grade niveladora dois dias antes da semeadura. Quanto ao histórico da área, foi cultivada soja durante três anos consecutivos. A semeadura do arroz (cultivar BRS Sertanejo) foi realizada no dia 20 de dezembro de 2009, com espaçamento entre linhas de $0,20 \mathrm{~m}$, com 80 sementes distribuídas por metro de sulco. A adubação de base NPK foi constituída por $150 \mathrm{~kg} \mathrm{ha}^{-1}$ da fórmula (05-30-15), distribuídos ao longo dos sulcos. A adubação de cobertura foi realizada com a aplicação de $160 \mathrm{~kg} \mathrm{ha}^{-1}$ da fórmula 20-00-00, sendo metade aos $25 \mathrm{DAE}$ e o restante aos 32 DAE.

O delineamento experimental foi o de blocos ao acaso, em esquema fatorial $5 \times 3$, compostos pelos tratamentos herbicidas penoxsulam (36 $\mathrm{g} \mathrm{ha}^{-1}$ ); bispyribac- Na (50 $\left.\mathrm{g} \mathrm{ha}^{-1}\right)$, pirazosulfuron-ethyl $\left(20 \mathrm{~g} \mathrm{ha}^{-1}\right)$, 2,4-D (670 $\left.\mathrm{g} \mathrm{ha}^{-1}\right)$ e testemunha capinada. Os herbicidas foram aplicados em três épocas: 15 ,
30 e 45 dias após a emergência (DAE), perfazendo 15 tratamentos, com quatro repetições. Cada parcela foi composta por $4 \mathrm{~m}$ de largura (20 linhas da cultura) e $4 \mathrm{~m}$ de comprimento. Para a área útil, foi descartado $1 \mathrm{~m}$ de cada lado da parcela e $1 \mathrm{~m}$ nas extremidades, perfazendo $9 \mathrm{~m}^{2}$ de área útil.

Os tratamentos foram aplicados com um pulverizador costal pressurizado com $\mathrm{CO}_{2}$, acoplado à barra com quatro pontas de pulverização XR 110.020 e volume de calda equivalente a $125 \mathrm{~L} \mathrm{ha}^{-1}$.

Aos 7, 14 e 28 dias após a aplicação (DAA) dos herbicidas, foram realizadas as seguintes avaliações: fitotoxicidade à cultura, por meio de notas visuais, variando de 0 a $100 \% \mathrm{em}$ relação à testemunha, em que 0 é ausência de injúrias e 100 a morte das plantas; altura de plantas, medindo-se aleatoriamente 20 plantas por parcela, por meio de uso de trena graduada; e fitomassa seca de plantas,

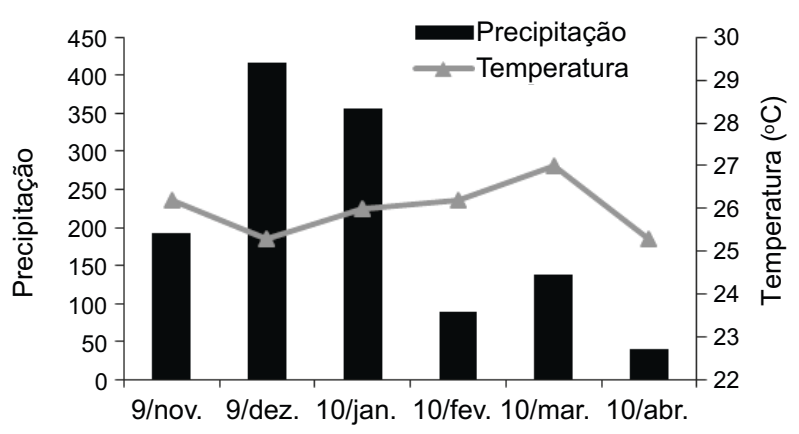

Fonte: Estação experimental do Inmet em Nova Xavantina-MT.

Figura 1 - Precipitação (mm) e temperatura média $\left({ }^{\circ} \mathrm{C}\right)$ mensal ocorrida durante a condução do experimento.

Tabela 1 - Composição química do solo (0-20 cm) da área experimental antes da instalação do experimento, na safra 2007/2008, em Nova Xavantina-MT

\begin{tabular}{|c|c|c|c|c|c|c|c|}
\hline $\mathrm{pH}$ & $\mathrm{P}($ Mehlich $)$ & $\mathrm{K}$ & $\mathrm{Ca}$ & $\mathrm{Mg}$ & $\mathrm{Al}$ & $\mathrm{H}+\mathrm{Al}$ & $\mathrm{M} . \mathrm{O} .^{-\prime}$ \\
\hline$\left(\mathrm{CaCl}_{2}\right)$ & \multicolumn{2}{|c|}{$\left(\mathrm{mg} \mathrm{dm}^{-3}\right)$} & \multicolumn{6}{c|}{$\left(\mathrm{cmol}_{\mathrm{c}} \mathrm{dm}^{-3}\right)$} & $\left(\mathrm{g} \mathrm{dm}^{-3}\right)$ \\
\hline 5,2 & 11,6 & 70,0 & 2,7 & 0,8 & 0,1 & 5,2 & 29,0 \\
\hline $\mathrm{V}^{2 /}$ & $\mathrm{CTC}^{3 /}$ & $\mathrm{Fe}$ & $\mathrm{B}$ & $\mathrm{Mn}$ & $\mathrm{Zn}$ & $\mathrm{Cu}$ & $\mathrm{S}$ \\
\hline$(\%)$ & $\left(\mathrm{cmol}_{\mathrm{c}} \mathrm{dm}^{-3}\right)$ & \multicolumn{7}{|c|}{$\left(\mathrm{mg} \mathrm{dm}^{-3}\right)$} \\
\hline 41 & 8,8 & 44 & 0,2 & 24 & 1,5 & 2,4 & 6,4 \\
\hline
\end{tabular}

1/ M.O.: matéria orgânica; $\stackrel{2}{2}$ V\%: saturação por bases; $\stackrel{3}{2}$ CTC: capacidade de troca catiônica. 
coletando-se 10 plantas por parcela, que posteriormente foram secas em estufa a $70^{\circ} \mathrm{C}$ até obtenção do peso constante.

A quantidade de panículas por $\mathrm{m}^{-2}$ e de grãos por panícula foi avaliada em précolheita. A produtividade foi avaliada no ponto de colheita, aos 115 dias após a semeadura, com padronização para $13 \%$ de umidade nos grãos.

Após a coleta e tabulação dos dados, efetuou-se a análise de variância, sendo as médias das variáveis significativas agrupadas pelo critério de Tukey a 5\% de significância, utilizando o programa estatístico Sisvar. Quanto à análise dos dados de fitotoxicidade, estes foram transformados para arc seno $(x+1)^{0.5}$.

\section{RESULTADOS E DISCUSSÃO}

Ao analisar os resultados de fitotoxicidade, observou-se que houve interação significativa entre os fatores herbicidas e épocas de aplicação, aos 7, 14 e 28 dias após a aplicação (DAA) dos herbicidas (Tabela 2). O bispyribac-Na foi o único herbicida a ocasionar fitotoxicidade visual nas plantas, aos 15 e 30 dias após a emergência de arroz (DAE), com sintomas de clorose acentuada (Tabela 3). O mecanismo de ação desse herbicida está inserido no grupo dos inibidores da enzima ALS (acetolactato sintetase), chave nos processos de biossintese dos aminoácidos valina, leucina e isoleucina, nos quais a tolerância de plantas está relacionada à alteração do gene responsável pela codificação dessa enzima (Rodrigues \& Almeida, 2005). Contudo, estudos mostraram que a resistência de plantas aos herbicidas inibidores da ALS pode estar relacionada à anatomia das folhas e raízes, em razão da presença de cutículas mais espessas e compostos lipídicos, que prejudicam a absorção desses herbicidas, além de alterações gênicas em cada cultivar de arroz de terras altas (Corbett $\&$ Tardif, 2006).

Esses resultados demonstram que o uso desse herbicida até $30 \mathrm{DAE}$ pode comprometer a cultura, uma vez que o estádio de perfilhamento inicia-se após a emissão da terceira folha. Por outro lado, sua aplicação aos $45 \mathrm{DAE}$ não ocasionou fitotoxicidade, em razão de a planta já apresentar capacidade de metabolização do herbicida. Maior capacidade de metabolização do herbicida pela cultura, associada à diferenciação morfológica das plantas, como espessura da cutícula (Vidal, 2002) e elevado índice de área foliar (Stone \& Pereira, 1994) aos 45 DAE, pode explicar a ausência do efeito tóxico às plantas. Os mecanismos de metabolização dessa molécula ainda são desconhecidos (Rodrigues \& Almeida, 2005; Rajguru et al., 2005).

Sanchonete et al. (2009) observaram que bispyribac-Na aplicado no início do desenvolvimento do arroz inundado provocou injúrias no crescimento de raízes e parte aérea das plantas até os 15 DAA. Contudo, esses autores observaram que as plantas conseguiram se recuperar aos 30 DAA, apresentando valores similares aos da testemunha capinada.

Quanto à altura de plantas, houve efeito significativo dos fatores herbicidas e épocas de aplicação analisados de forma isolada, exceto na avaliação aos 28 DAA (Tabela 2). Observou-se redução na altura de plantas tratadas com penoxsulam, bispyribac-Na e pirazosulfuron-ethyl quando aplicados de forma precoce, aos 15 e $30 \mathrm{DAE}$ do arroz (Tabela 4). Esses resultados reforçam a potencialidade de ocorrência de efeito deletério dos herbicidas (penoxsulam e pirazosulfuronethyl) em arroz, mesmo na ausência de sinais de clorose foliar, número e tamanho de folhas. Todavia, no presente estudo, as plantas de arroz conseguiram se recuperar quanto aos efeitos deletérios na redução de altura, o que pode ser atestado pela não significância entre os tratamentos com herbicidas em relação à testemunha capinada aos 28 DAA. Esses resultados corroboram os de Concenço et al. (2006) e Sanchonete et al. (2009), em que variedades de arroz irrigado não apresentaram redução na altura de plantas a partir de 30 dias após a aplicação dos herbicidas penoxsulam e bispyribac-Na.

Ao observar o acúmulo de fitomassa pela plantas de arroz submetidas a diferentes épocas de aplicação e herbicidas, houve efeito dos fatores de variação de forma isolada, exceto para o efeito de herbicidas aos 7 e 28 DAA (Tabela 2). Os herbicidas 2,4-D e pirazossulfuron-ehtyl possibilitaram ao arroz de terras altas os maiores acúmulos de fitomassa na avaliação aos 14 DAA. Todavia, esse parâmetro não foi significativo aos 28 DAA, 
Tabela 2 - Análise de variância (valores de F) para os diferentes efeitos em altura, fitomassa, fitoxicidade e componentes de produção do arroz cv. Sertanejo, na safra 2009/2010, em Nova Xavantina-MT

\begin{tabular}{|c|c|c|c|c|c|c|}
\hline \multirow{2}{*}{ Causa da variação } & \multicolumn{3}{|c|}{ Fitotoxicidade (DAA) } & \multicolumn{3}{|c|}{ Altura (DAA) } \\
\hline & 7 & 14 & 28 & 7 & 14 & 28 \\
\hline Herbicidas & $503^{*}$ & $1208^{*}$ & $384^{*}$ & $6,60^{*}$ & $6,09 *$ & $2,29^{\mathrm{ns}}$ \\
\hline Épocas & $145^{*}$ & $302 *$ & $140^{*}$ & $764 *$ & $740^{*}$ & $174^{*}$ \\
\hline Herbicidas $\mathrm{x}$ épocas & $145^{*}$ & $302 *$ & $140^{*}$ & $1,21^{\mathrm{ns}}$ & $1,42^{\mathrm{ns}}$ & $0,34^{\mathrm{ns}}$ \\
\hline $\mathrm{CV}(\%)$ & 12,76 & 9,12 & 13,13 & 6,85 & 5,40 & 5,09 \\
\hline \multirow{2}{*}{ Causa da variação } & \multicolumn{3}{|c|}{ Fitomassa (DAA) } & Número de & Quantidade de & \\
\hline & 7 & 14 & 28 & panículas $\mathrm{m}^{-2}$ & grãos panícula ${ }^{-1}$ & Produtividade \\
\hline Herbicidas & $0,92^{\mathrm{ns}}$ & $2,54 * *$ & $1,21^{\mathrm{ns}}$ & $3,60 * *$ & $1,10^{\mathrm{ns}}$ & $35,98^{*}$ \\
\hline Épocas & $665^{*}$ & $241^{*}$ & $84,53 *$ & $12,41 *$ & $0,13^{\mathrm{ns}}$ & $63,99 *$ \\
\hline Herbicidas x épocas & $0,24^{\mathrm{ns}}$ & $1,18^{\mathrm{ns}}$ & $1,01^{\mathrm{ns}}$ & $1,03^{\text {ns }}$ & $0,65^{\text {ns }}$ & $7,17 *$ \\
\hline $\mathrm{CV}(\%)$ & 13,18 & 18,27 & 23,50 & 17,19 & 29,99 & 12,20 \\
\hline
\end{tabular}

* e ${ }^{* *}$ significativo a 1 e $5 \%$, respectivamente; ${ }^{\text {ns }}$ não significativo. 7,14 e 28 dias após a aplicação dos tratamentos (DAA).

Tabela 3 - Fitotoxicidade em plantas de arroz submetido à aplicação dos herbicidas em diferentes épocas após a emergência da cultura, na safra 2009/2010, em Nova Xavantina-MT

\begin{tabular}{|c|c|c|c|c|}
\hline \multirow{2}{*}{ Herbicida } & \multicolumn{3}{|c|}{ Época de aplicação dos herbicidas } & \multirow{2}{*}{ Média } \\
\hline & $15 \mathrm{DAE}^{*}$ & $30 \mathrm{DAE}$ & $45 \mathrm{DAE}$ & \\
\hline & \multicolumn{3}{|c|}{ Fitotoxicidade $(\%)-7 \mathrm{DAA}^{* *}$} & \\
\hline Penoxsulam $\left(36 \mathrm{~g} \mathrm{ha}^{-1}\right)$ & $0 \mathrm{Aa}$ & $0 \mathrm{Aa}$ & $0 \mathrm{Aa}$ & 0 \\
\hline Pirazosulfuron-ethyl $\left(20 \mathrm{~g} \mathrm{ha}^{-1}\right)$ & $0 \mathrm{Aa}$ & $0 \mathrm{Aa}$ & $0 \mathrm{Aa}$ & 0 \\
\hline Bispyribac-Na $\left(50 \mathrm{~g} \mathrm{ha}^{-1}\right)$ & $18,75 \mathrm{Ab}$ & $40 \mathrm{Bc}$ & $0 \mathrm{Aa}$ & 19,58 \\
\hline 2,4-D $\left(670 \mathrm{~g} \mathrm{ha}^{-1}\right)$ & $0 \mathrm{Aa}$ & $0 \mathrm{Aa}$ & $0 \mathrm{Aa}$ & 0 \\
\hline Testemunha & $0 \mathrm{Aa}$ & $0 \mathrm{Aa}$ & $0 \mathrm{Aa}$ & 0 \\
\hline \multirow[t]{2}{*}{ Média } & 3,75 & 8,0 & 0,0 & 3,91 \\
\hline & \multicolumn{3}{|c|}{ Fitotoxicidade $(\%)-14 \mathrm{DAA}^{* *}$} & Média \\
\hline Penoxsulam $\left(36 \mathrm{~g} \mathrm{ha}^{-1}\right)$ & $0 \mathrm{Aa}$ & $0 \mathrm{Aa}$ & $0 \mathrm{Aa}$ & 0 \\
\hline Pirazosulfuron-ethyl $\left(20 \mathrm{~g} \mathrm{ha}^{-1}\right)$ & $0 \mathrm{Aa}$ & $0 \mathrm{Aa}$ & $0 \mathrm{Aa}$ & 0 \\
\hline Bispyribac-Na $\left(50 \mathrm{~g} \mathrm{ha}^{-1}\right)$ & $37,5 \mathrm{Bb}$ & $37,5 \mathrm{Bb}$ & $0 \mathrm{Aa}$ & 25 \\
\hline $2,4-\mathrm{D}\left(670 \mathrm{~g} \mathrm{ha}^{-1}\right)$ & $0 \mathrm{Aa}$ & $0 \mathrm{Aa}$ & $0 \mathrm{Aa}$ & 0 \\
\hline Testemunha & $0 \mathrm{Aa}$ & $0 \mathrm{Aa}$ & $0 \mathrm{Aa}$ & 0 \\
\hline \multirow[t]{2}{*}{ Média } & 7,5 & 7,5 & 0 & 5 \\
\hline & \multicolumn{3}{|c|}{ Fitotoxicidade $(\%)-28 \mathrm{DAA}^{* *}$} & Média \\
\hline Penoxsulam $\left(36 \mathrm{~g} \mathrm{ha}^{-1}\right)$ & $0 \mathrm{Aa}$ & $0 \mathrm{Aa}$ & $0 \mathrm{Aa}$ & 0 \\
\hline Pirazosulfuron-ethyl $\left(20 \mathrm{~g} \mathrm{ha}^{-1}\right)$ & $0 \mathrm{Aa}$ & $0 \mathrm{Aa}$ & $0 \mathrm{Aa}$ & 0 \\
\hline Bispyribac-Na $\left(50 \mathrm{~g} \mathrm{ha}^{-1}\right)$ & $10 \mathrm{Bb}$ & $37,5 \mathrm{Bc}$ & $0 \mathrm{Aa}$ & 15,83 \\
\hline 2,4-D $\left(670 \mathrm{~g} \mathrm{ha}^{-1}\right)$ & $0 \mathrm{Aa}$ & $0 \mathrm{Aa}$ & $0 \mathrm{Aa}$ & 0 \\
\hline Testemunha & $0 \mathrm{Aa}$ & $0 \mathrm{Aa}$ & $0 \mathrm{Aa}$ & 0 \\
\hline Média & 2 & 7,5 & 0 & 3,16 \\
\hline
\end{tabular}

Médias seguidas pelas mesmas letras, maiúsculas na coluna (vertical) e minúsculas na linha (horizontal), não diferem estatisticamente entre si pelo teste de Tukey a $5 \%$ de probabilidade. * Dias após a emergência da cultura.** Dias após a aplicação dos herbicidas.

demonstrando que as plantas conseguiram se recuperar após a intoxicação causada pelo herbicida (Tabela 5). Essas observações também foram relatadas por Sanchonete et al. (2009) em arroz irrigado. Concenço et al. (2006) também observaram que o penoxsulam não 
Tabela 4 - Altura das plantas de arroz depois da aplicação dos herbicidas em diferentes épocas após a emergência da cultura, na safra 2009/2010, em Nova Xavantina-MT

\begin{tabular}{|c|c|c|c|c|}
\hline \multirow{2}{*}{ Herbicida } & \multicolumn{3}{|c|}{ Época de aplicação dos herbicidas } & \multirow{2}{*}{ Média } \\
\hline & $15 \mathrm{DAE}^{*}$ & $30 \mathrm{DAE}$ & $45 \mathrm{DAE}$ & \\
\hline & \multicolumn{3}{|c|}{ Altura $(\mathrm{cm})-7 \mathrm{DAA}^{* *}$} & \\
\hline Penoxsulam $\left(36 \mathrm{~g} \mathrm{ha}^{-1}\right)$ & $31,2 \mathrm{~B}$ & $74,5 \mathrm{~A}$ & $91,5 \mathrm{~A}$ & 65,7 \\
\hline Pirazosulfuron-ethyl $\left(20 \mathrm{~g} \mathrm{ha}^{-1}\right)$ & $33,3 \mathrm{AB}$ & $71,3 \mathrm{~A}$ & $90,5 \mathrm{~A}$ & 65,0 \\
\hline Bispyribac-Na $\left(50 \mathrm{~g} \mathrm{ha}^{-1}\right)$ & $31,2 \mathrm{~B}$ & $69,5 \mathrm{~A}$ & $86,0 \mathrm{~A}$ & 62,2 \\
\hline $2,4-\mathrm{D}\left(670 \mathrm{~g} \mathrm{ha}^{-1}\right)$ & $41,3 \mathrm{~A}$ & $72,5 \mathrm{~A}$ & $93,6 \mathrm{~A}$ & 69,1 \\
\hline Testemunha & $42,2 \mathrm{~A}$ & $75,3 \mathrm{~A}$ & $94,7 \mathrm{~A}$ & 70,7 \\
\hline \multirow[t]{2}{*}{ Média } & 35,8 & 72,6 & 91,2 & 66,5 \\
\hline & \multicolumn{3}{|c|}{ Altura $(\mathrm{cm})-14 \mathrm{DAA}^{* *}$} & Média \\
\hline Penoxsulam $\left(36 \mathrm{~g} \mathrm{ha}^{-1}\right)$ & $45,6 \mathrm{AB}$ & $77,9 \mathrm{~B}$ & $93,5 \mathrm{~A}$ & 72,3 \\
\hline Pirazosulfuron-ethyl $\left(20 \mathrm{~g} \mathrm{ha}^{-1}\right)$ & $52,5 \mathrm{~A}$ & $84,6 \mathrm{AB}$ & $96,6 \mathrm{~A}$ & 77,9 \\
\hline Bispyribac-Na $\left(50 \mathrm{~g} \mathrm{ha}^{-1}\right)$ & $43,8 \mathrm{~B}$ & $78,4 \mathrm{~B}$ & $91,6 \mathrm{~A}$ & 71,2 \\
\hline 2,4-D $\left(670 \mathrm{~g} \mathrm{ha}^{-1}\right)$ & $45,5 \mathrm{AB}$ & $81,3 \mathrm{AB}$ & $93,3 \mathrm{~A}$ & 73,4 \\
\hline Testemunha & $47,1 \mathrm{AB}$ & $89,0 \mathrm{~A}$ & $94,0 \mathrm{~A}$ & 76,7 \\
\hline \multirow[t]{2}{*}{ Média } & 46,9 & 82,2 & 93,8 & 74,3 \\
\hline & \multicolumn{3}{|c|}{ Altura $(\mathrm{cm})-28 \mathrm{DAA}^{* *}$} & Média \\
\hline Penoxsulam $\left(36 \mathrm{~g} \mathrm{ha}^{-1}\right)$ & 83,6 & 92,3 & 112,0 & $96,3^{\mathrm{n}}$ \\
\hline Pirazosulfuron-ethyl $\left(20 \mathrm{~g} \mathrm{ha}^{-1}\right)$ & 86,9 & 90,9 & 111,0 & 96,5 \\
\hline Bispyribac-Na $\left(50 \mathrm{~g} \mathrm{ha}^{-1}\right)$ & 81,2 & 89,5 & 110,0 & 93,7 \\
\hline $2,4-\mathrm{D}\left(670 \mathrm{~g} \mathrm{ha}^{-1}\right)$ & 87,5 & 90,4 & 114,0 & 97,6 \\
\hline Testemunha & 89,0 & 94,0 & 116,0 & 99,7 \\
\hline Média & 85,6 & 91,4 & 113,2 & 96,7 \\
\hline
\end{tabular}

Médias seguidas pelas mesmas letras maiúsculas na coluna não diferem estatisticamente entre si pelo teste de Tukey a 5\% de probabilidade.

* Dias após a emergência da cultura.** Dias após a aplicação dos herbicidas.

apresentou redução no acúmulo de fitomassa após 38 dias de tratamento no arroz irrigado. Por outro lado, esses mesmos autores observaram efeito deletério significativo desse herbicida no desenvolvimento de raízes.

No que se refere ao número de panículas por metro quadrado no arroz, também se verificou significância quanto aos efeitos da época de aplicação e do tipo de herbicida, embora não tenha havido a interação das fontes de variação (Tabela 2). As plantas submetidas à aplicação dos herbicidas aos 30 DAE destacaram-se na produção de panículas, o que pode estar relacionado às condições climáticas mais favoráveis para o seu desenvolvimento, imediatamente após a aplicação dos herbicidas, resultando em maior produção de panículas (Tabela 6), como já observado por Andes et al. (2007).

Quanto ao número de grãos por panícula, os tratamentos não apresentaram efeito significativo das fontes de variação avaliadas no arroz (Tabela 2). Por outro lado, houve efeito significativo da interação entre as épocas de aplicação e o tipo de herbicidas para a produtividade de grãos. Trabalhos mostram que variáveis como número de panículas e peso de grãos podem não se correlacionar com a produção (Stone \& Moreira, 2000; Oliveira et al., 2002), em razão da desuniformidade no estande, bem como para componentes de produção, como a radiação, o que dificulta sua medição e, consequentemente, proporciona altos coeficientes de variação.

A época de aplicação dos herbicidas que proporcionou maior produtividade de grãos foi 30 DAE (Tabela 6). Em aplicações precoces e tardias, aos 15 e $45 \mathrm{DAE}$, os herbicidas bispyribac-Na, penoxsulam e pirazosulfuronethyl apresentaram acentuada redução na produtividade. Esses resultados demonstram que a melhor época para uso desses herbicidas 
foi aos 30 DAE do arroz BRS Sertanejo, com destaque para o 2,4-D, que apresentou fitotoxicidade, altura, fitomassa e produtividade semelhantes às da testemunha capinada. Esses resultados estão de acordo com os de Cobucci \& Portela (2001), nos quais a aplicação de 2,4-D e clefoxydin foi recomendada para todos os cultivares de arroz de terras altas analisados, sem prejuízo da produtividade. Nesse mesmo estudo, observou-se que a época mais adequada para aplicação dos herbicidas em pós-emergência, em diferentes cultivares de arroz, foi aos 30 DAE. Isso é explicado pelo fato de que o arroz encontra-se em intenso perfilhamento antes dos $30 \mathrm{DAE}$, o que pode reduzir sensivelmente o número de panículas. $\mathrm{O}$ efeito deletério dos herbicidas bispyribac-Na, penoxsulam e pirazosulfuron-ethyl pode afetar a definição da indução floral e a redução de área fotossintética, o que reduz a translocação de fotoassimilados para os drenos, em razão da diminuição da área foliar, ocasionando menor número de panículas, como demonstrado na Tabela 5 (Cobucci \& Portela, 2001).

Ao analisar os resultados de forma geral, o herbicida penoxsulam, aplicado aos $30 \mathrm{DAE}$, destacou-se como melhor opção entre os herbicidas inibidores da ALS para uso em arroz de terras altas, cultivar BRS Sertanejo, por apresentar valores de fitotoxicidade, altura de plantas, fitomassa e componentes de produtividade semelhantes aos dos tratamentos com 2,4-D e testemunha. Todavia, deve-se ressaltar que a recomendação desse herbicida para o arroz de terras altas necessita de mais estudos, uma vez que o penoxsulam pode apresentar restrições em seu uso em função das condições edafoclimáticas. Embora o bispyribac-Na não tenha apresentado interferência na produtividade de grãos, a

Tabela 5 - Fitomassa das plantas de arroz depois da aplicação dos herbicidas em diferentes épocas após a emergência da cultura, na safra 2009/2010, em Nova Xavantina-MT

\begin{tabular}{|c|c|c|c|c|}
\hline \multirow{2}{*}{ Herbicida } & \multicolumn{3}{|c|}{ Época de aplicação dos herbicidas } & \multirow{2}{*}{ Média } \\
\hline & $15 \mathrm{DAE}^{*}$ & $30 \mathrm{DAE}$ & $45 \mathrm{DAE}$ & \\
\hline & \multicolumn{3}{|c|}{ Fitomassa (g $10^{-1}$ plantas) $7 \mathrm{DAA}^{* *}$} & \\
\hline Penoxsulam $\left(36 \mathrm{~g} \mathrm{ha}^{-1}\right)$ & 2,3 & 8,3 & 16,2 & $8,9^{\text {ns }}$ \\
\hline Pirazosulfuron-ethyl $\left(20 \mathrm{~g} \mathrm{ha}^{-1}\right)$ & 2,4 & 9,2 & 16,7 & 9,4 \\
\hline Bispyribac-Na $\left(50 \mathrm{~g} \mathrm{ha}^{-1}\right)$ & 2,3 & 8,7 & 16,0 & 9,0 \\
\hline $2,4-\mathrm{D}\left(670 \mathrm{~g} \mathrm{ha}^{-1}\right)$ & 2,5 & 8,5 & 16,7 & 9,2 \\
\hline Testemunha & 2,6 & 9,3 & 17,5 & 9,8 \\
\hline \multirow[t]{2}{*}{ Média } & $2,4 \mathrm{c}$ & $8,8 \mathrm{~b}$ & $16,6 \mathrm{a}$ & 9,3 \\
\hline & \multicolumn{3}{|c|}{ Fitomassa (g $10^{-1}$ plantas) $14 \mathrm{DAA}^{* *}$} & Média \\
\hline Penoxsulam $\left(36 \mathrm{~g} \mathrm{ha}^{-1}\right)$ & 3,8 & 12,2 & 18,2 & $11,4 \mathrm{~B}$ \\
\hline Pirazosulfuron-ethyl $\left(20 \mathrm{~g} \mathrm{ha}^{-1}\right)$ & 4,9 & 13,2 & 20,0 & $12,7 \mathrm{AB}$ \\
\hline Bispyribac-Na $\left(50 \mathrm{~g} \mathrm{ha}^{-1}\right)$ & 4,3 & 12,7 & 18,5 & $11,8 \mathrm{~B}$ \\
\hline 2,4-D $\left(670 \mathrm{~g} \mathrm{ha}^{-1}\right)$ & 3,8 & 16,5 & 21,7 & $14,0 \mathrm{~A}$ \\
\hline Testemunha & 3,8 & 14,0 & 22,5 & $13,4 \mathrm{AB}$ \\
\hline \multirow[t]{2}{*}{ Média } & $4,1 \mathrm{c}$ & $13,7 \mathrm{~b}$ & $20,2 \mathrm{a}$ & 12,7 \\
\hline & \multicolumn{3}{|c|}{ Fitomassa (g $10^{-1}$ plantas) $28 \mathrm{DAA}^{* *}$} & Média \\
\hline Penoxsulam $\left(36 \mathrm{~g} \mathrm{ha}^{-1}\right)$ & $11,7 \mathrm{~A}$ & $20,0 \mathrm{~A}$ & $32,2 \mathrm{AB}$ & $21,3^{\text {ns }}$ \\
\hline Pirazosulfuron-ethyl $\left(20 \mathrm{~g} \mathrm{ha}^{-1}\right)$ & $13,5 \mathrm{~A}$ & $22,5 \mathrm{~A}$ & $29,0 \mathrm{~B}$ & 21,6 \\
\hline Bispyribac-Na $\left(50 \mathrm{~g} \mathrm{ha}^{-1}\right)$ & $12,0 \mathrm{~A}$ & $21,0 \mathrm{~A}$ & $34,0 \mathrm{AB}$ & 22,3 \\
\hline $2,4-\mathrm{D}\left(670 \mathrm{~g} \mathrm{ha}^{-1}\right)$ & $13,2 \mathrm{~A}$ & $21,2 \mathrm{~A}$ & $39,2 \mathrm{AB}$ & 24,5 \\
\hline Testemunha & $14,0 \mathrm{~A}$ & $21,2 \mathrm{~A}$ & $40,0 \mathrm{~A}$ & 25,0 \\
\hline Média & $12,9 \mathrm{c}$ & $21,2 \mathrm{~b}$ & $34,9 \mathrm{a}$ & 23,0 \\
\hline
\end{tabular}

Médias seguidas pelas mesmas letras maiúsculas na coluna não diferem estatisticamente entre si pelo teste de Tukey a $5 \%$ de probabilidade. ${ }^{\text {ns }}$ Não significativo. * Dias após a emergência da cultura. ${ }^{* *}$ Dias após a aplicação dos herbicidas. 
Tabela 6 - Panículas, grãos por panícula e produtividade de grãos depois da aplicação dos herbicidas em diferentes épocas após a emergência da cultura, na safra 2009/2010, em Nova Xavantina-MT

\begin{tabular}{|c|c|c|c|c|}
\hline \multirow{2}{*}{ Herbicida } & \multicolumn{3}{|c|}{ Época de aplicação dos herbicidas } & \multirow{2}{*}{ Média } \\
\hline & $15 \mathrm{DAE}^{*}$ & $30 \mathrm{DAE}$ & $45 \mathrm{DAE}$ & \\
\hline & \multicolumn{3}{|c|}{ Número de panículas $\mathrm{m}^{-2}$} & \\
\hline Penoxsulam $\left(36 \mathrm{~g} \mathrm{ha}^{-1}\right)$ & 121 & 159 & 121 & $134 \mathrm{AB}$ \\
\hline Pirazosulfuron-ethyl $\left(20 \mathrm{~g} \mathrm{ha}^{-1}\right)$ & 118 & 164 & 107 & $129 \mathrm{~B}$ \\
\hline Bispyribac-Na $\left(50 \mathrm{~g} \mathrm{ha}^{-1}\right)$ & 119 & 147 & 97 & $121 \mathrm{~B}$ \\
\hline $2,4-\mathrm{D}\left(670 \mathrm{~g} \mathrm{ha}^{-1}\right)$ & 147 & 171 & 137 & $152 \mathrm{~A}$ \\
\hline Testemunha & 148 & 168 & 158 & $158 \mathrm{~A}$ \\
\hline \multirow[t]{2}{*}{ Média } & $130 \mathrm{~b}$ & $162 \mathrm{a}$ & $124 \mathrm{~b}$ & 139 \\
\hline & \multicolumn{3}{|c|}{ Grãos por panícula } & Média \\
\hline Penoxsulam $\left(36 \mathrm{~g} \mathrm{ha}^{-1}\right)$ & 81 & 124 & 95 & $100^{\mathrm{ns}}$ \\
\hline Pirazosulfuron-ethyl $\left(20 \mathrm{~g} \mathrm{ha}^{-1}\right)$ & 119 & 106 & 134 & 119 \\
\hline Bispyribac-Na $\left(50 \mathrm{~g} \mathrm{ha}^{-1}\right)$ & 118 & 116 & 124 & 119 \\
\hline 2,4-D $\left(670 \mathrm{~g} \mathrm{ha}^{-1}\right)$ & 115 & 113 & 101 & 109 \\
\hline Testemunha & 113 & 123 & 113 & 116 \\
\hline \multirow[t]{2}{*}{ Média } & 107 & 116 & 113 & 112 \\
\hline & \multicolumn{3}{|c|}{ Produtividade $\left(\mathrm{kg} \mathrm{ha}^{-1}\right)$} & Média \\
\hline Penoxsulam $\left(36 \mathrm{~g} \mathrm{ha}^{-1}\right)$ & $1.909 \mathrm{CDb}$ & $2.558 \mathrm{ABa}$ & $1.054 \mathrm{Bc}$ & 1.840 \\
\hline Pirazosulfuron-ethyl $\left(20 \mathrm{~g} \mathrm{ha}^{-1}\right)$ & $1.912 \mathrm{CDab}$ & $2.053 \mathrm{Ba}$ & $1.258 \mathrm{Bb}$ & 1.741 \\
\hline Bispyribac-Na $\left(50 \mathrm{~g} \mathrm{ha}^{-1}\right)$ & $2.079 \mathrm{BCb}$ & $2.551 \mathrm{ABa}$ & $987 \mathrm{Bc}$ & 1.873 \\
\hline $2,4-\mathrm{D}\left(670 \mathrm{~g} \mathrm{ha}^{-1}\right)$ & $2.530 \mathrm{ABab}$ & $2.768 \mathrm{Aa}$ & $2.102 \mathrm{Ab}$ & 2.467 \\
\hline Testemunha & $2.807 \mathrm{Aa}$ & $2.657 \mathrm{ABa}$ & $2.557 \mathrm{Aa}$ & 2.673 \\
\hline Média & 2.247 & 2.517 & 1.519 & 2.118 \\
\hline
\end{tabular}

Médias seguidas pelas mesmas letras, maiúsculas na coluna (vertical) e minúsculas na linha (horizontal), não diferem estatisticamente entre si pelo teste de Tukey a $5 \%$ de probabilidade. ${ }^{*}$ Dias após a emergência da cultura.

intoxicação inicial, atestada pela elevada presença de manchas necróticas, redução no número e tamanho das folhas, principalmente quando aplicado até 15 e $30 \mathrm{DAE}$, pode restringir sua recomendação, uma vez que as condições edafoclimáticas podem interferir no potencial de recuperação das plantas (Cobucci $\&$ Portella, 2001; Andes et al., 2007).

Andes et al. (2007) observaram que o desempenho das variáveis área foliar, altura de plantas, fitomassa da parte aérea, número de colmos e panículas das plantas de arroz irrigado foi satisfatório, com o aumento da disponibilidade de água no estádio de quatro folhas do cultivar BRS Pelota quando se utilizou bispyribac-Na. Esses resultados mostram que a ocorrência mais frequente de chuvas nos estádios iniciais de desenvolvimento, logo após a aplicação do herbicida, pode reduzir o efeito fitotóxico do herbicida nas plantas.

\section{LITERATURA CITADA}

ANDES, A. et al. Desempenho do cultivar de arroz BRS pelo e controle de capim-arroz (Echinochloa spp.) submetidos a quatro épocas de entrada d'água após aplicação de doses reduzidas de herbicidas. Planta Daninha, v. 25, n. 4, p. 859-867, 2007.

CARLESSO, R. et al. Índice de área foliar e altura de plantas de arroz submetidas a diferentes práticas de manejo. R. Bras. Eng. Agríc. Amb., v. 2, n. 2, p. 268-272, 1998

COBUCCI, T; PORTELA, C. Seletividade de herbicidas aplicados em diferentes estádios de desenvolvimento na cultura do arroz de terras altas. Planta Daninha, v. 19, n. 3, p. 359-366, 2001.

COMPANHIA NACIONAL DE ABASTECIMENTO CONAB. 12 ${ }^{\circ}$ Levantamento da Produção de Grãos Safra 2009/10. Brasília: 2010. Disponível em:< http:// www.CONAB.gov.br>. Acesso em: 8 set. 2010 
CONCENÇO, G. et al. Efeito de herbicidas aplicados em préemergência e momentos de início da irrigação no crescimento de plantas de arroz. Planta Daninha, v. 24, n. 2, p. 295-301, 2006.

CORBETT, C. L.; TARDIF, F. J. Detection of resistance to acetolactate synthase inhibitors in weeds with emphasis on DNA-based techniques: a review. Pest Manag. Sci., v. 62, n. 7 , p. 584-597.

COSTA, F. S. et al. Aumento de matéria orgânica num latossolo bruno em plantio direto. Ci. Rural, v. 34, n. 2, p. 587-589, 2004.

EMPRESA BRASILEIRA DE PESQUISA

AGROPECUÁRIA - EMBRAPA. Centro Nacional de Pesquisa de Solos. Sistema Brasileiro de Classificação de Solos. Rio de Janeiro, 1999. 412 p.

GASPARIM, L. et al. Temperatura no perfil do solo utilizando duas densidades de cobertura e solo nu. Acta Sci. Agron., v. 27, n. 1, p. 107-115, 2005.

LEITE, C. R. F.; ALMEIDA, J. C. V.; PRETE, C. E. C. Aspectos fisiológicos, bioquímicos e agronômicos dos herbicidas inibidores da ALS (AHAS). Londrina: 1998. 68 p

MACHADO, R. F. et al. Reflexos do mecanismos de ação de herbicidas na qualidade fisiológica de sementes e na atividade enzimática em plântulas de arroz. R. Bras. Sementes, v. 28, n. 1, p. 151-160, 2006.

OLIVEIRA, T. K.; CARVALHO, G. J.; MORAES, R. N. S. Plantas e cobertura e seus efeitos sobre o feijoeiro em plantio direto. Pesq. Agropec. Bras., v. 37, n. 8, p. 1079-1087, 2002.
PACHECO, L. P. et al. Sobressemeadura da soja como técnica para supressão da emergência de plantas daninhas. Planta Daninha, v. 27, n. 3, p. 455-463, 2009.

RAHMAN, M. A. Critical period of weed competition in transplanted aman rice. Bangladesh J. Sci. Ind. Res., v. 27, n. 1, p. 151-156, 1992.

RAJGURU, S. N. et al. Mutations in the red rice ALS gene associated with resistance to imazethapyr. Weed Sci., v. 53, n. 5 , p. 567-577, 2005.

RODRIGUES, B. N.; ALMEIDA, F. S. Guia de herbicidas. 5.ed. Londrina: Edição dos Autores, 2005. 591 p.

SANCHOTENE, D. M. et al. Effect os ALS and ACCASE inhibitor herbicides over the morphology of watered rice crops. R. FZVA, v. 16, n. 1, p. 79-85, 2009.

STONE, L. F.; PEREIRA, A. L. Sucessão arroz-feijão irrigados por aspersão: efeitos do espaçamento entre linhas, adubação e cultivar no crescimento, desenvolvimento radicular e consumo de água do arroz. Pesq. Agropec. Bras., v. 29, n. 6 , p. 939-954-1592, 1994.

STONE, L. F.; MOREIRA, J. A. A. Efeitos de sistemas de preparo de solo no uso da água e na produtividade do feijoeiro. Pesq. Agropec. Bras., v. 35, n. 4, p. 835-841, 2000 .

VIDAL, R. Ação dos herbicidas. Porto Alegre: 2002. 89 p.

WANDER, A. E. A competitividade do agronegócio brasileiro de arroz. Custos e Agronegócio. Santo Antônio de Goiás: Embrapa Arroz e Feijão, 2006. p. 1-14 